\title{
Neural control of the endocrine pancreas
}

\section{By David R. Matthews and Anne Clark, Diabetes Research Laboratories, Radcliffe Infirmary, Woodstock Road, Oxford OX2 $6 \mathrm{HE}$}

It has been known from the I 9 th century that the pancreas is innervated. In his doctoral thesis Langerhans ( 1869 ) noted that the 'Zellhaufen' or clusters of cells, which he observed and which were later called the Islets of Langerhans had certain connections with the nervous system. There was of course, at this stage, no evidence for the function of these islets. Earlier Bernard (1849) had made an important physiological observation that lesions made at the base of the fourth ventricle in dogs resulted in glycosuria. Thus both anatomical and physiological clues about the innervation of the pancreas have been recognized for more than a century. Advances in understanding the importance of the innervation of the pancreas has, however, been slow, due to the fact that, after the isolation of insulin, it became evident that insulin release was regulated largely by blood glucose levels and there seemed no compelling reason to investigate neural control. It remains true that in the whole animal, in the perfused pancreas (Samols \& Weir, 1979), or even in isolated islets (Ashcroft, 1980), that glucose and many other substrates can be a sufficient stimulus for insulin release. Neural inputs to the pancreas are therefore modulating rather than initiating influences but their importance should not be underestimated.

\section{Anatomical evidence}

Parasympathetic fibres of the vagus and sympathetic nerves from the splanchnic trunk innervate the pancreas, and nerve networks can be seen adjacent to some islets (Plate $\mathrm{I}$ ). However, there is sparse ultrastructural evidence for a functional continuity between the nerves and the endocrine cells. Peptidergic neurones containing vaso-active intestinal polypeptide (VIP) (Bishop et al. I980), substance-P, enkephalin and gastrin-cholecystokinin (CCK) (Larsson, 1979) have been identified by immunocytochemistry. Although dense networks of VIP-containing fibres surround the islets, peptidergic nerves are also associated with numerous ganglia found throughout the pancreas (Bishop et al. 1980). These ganglia may be areas of integration of extrinsic and intrinsic nerve signals, and may even be the sites of initiation of pulsatile hormone secretion (Stagner \& Samols, 1985).

\section{Physiological studies on pancreatic secretion}

Insulin and glucagon. The studies of Frohman et al. (1967) were a marked step forward in our understanding of the importance of the pancreatic innervation. Using the then relatively new immunoassay technique for measuring insulin, they 
demonstrated that stimulation of the vagal nerve in the neck of the dog caused a marked increase in insulin secretion. Blood glucose rose slightly after the vagal stimulation from which they concluded that either the innervation might affect the liver as well, or that the glucogenic effect of glucagon simultaneously secreted from the pancreas might precede the effects of insulin. Porte et al. (1973) showed that this phenomenon was observable in a perfused pancreas when the pancreatic duodenal nerve supply was stimulated local to the pancreas. These studies also showed that such effects could be blocked by atropine, suggesting stimulation by cholinergic nerves from the parasympathetic system mediated through the vagus.

In a series of elegant experiments using conscious adrenalectomized calves with implanted electrodes, Bloom \& Edwards (1980) demonstrated that stimulation of the splanchnic nerves caused a marked elevation of glucagon as well as insulin and that this rise in glucagon preceded the insulin secretion. They also found a rise in blood glucose on stimulation which could be blocked by atropine. The glucagon response was relatively insensitive to changes in plasma glucose concentration, whereas the insulin response could be amplified considerably by relative hyperglycaemia.

Pancreatic polypeptide. Although the physiological role of pancreatic polypeptide (PP) has yet to be determined, the rise in PP secretion during a meal in normal subjects is considerably reduced after truncal vagotomy (Schwartz et al. 1976). Vagal stimulation in pigs induced an increased PP secretion which was atropine-sensitive, so that cholinergic stimulation may regulate stimulated release even though basal secretion may be unaffected by neural blockade (Schwartz et al. 1978).

Somatostatin. Somatostatin-containing D-cells are situated adjacent to insulin and glucagon cells and it has been proposed that somatostatin may have a paracrine role in regulating islet function (Larsson et al. 1979). Somatostatin secretion is also affected by extrinsic nerves; vagal stimulation elicits an atropine-sensitive increase in secretion from the isolated pig pancreas and splanchnic nerve stimulation can elicit either increased ( $\alpha$-adrenergic activation) or decreased ( $\beta$-adrenergic activation) somatostatin release (Holst et al. 1983). The fact that somatostatin secretion itself may be enhanced by VIP (Szecowka et al. 1980) could indicate the existence of an intrinsic pancreatic nerve network regulating its secretion.

\section{Function of the nervous supply to the pancreas}

Control from higher centres. Cephalic phase insulin release has been elegantly described by Berthoud \& Jeanrenaud (1982) using rats both fed and sham-fed, before and after vagotomy. Feeding provoked a prompt rise in insulin secretion and this was not dependent on food reaching the fundus of the stomach. After vagotomy, this cephalic phase reflex was abolished, though substrate-stimulated insulin release was unaffected. Cephalic phase reflexes can also be demonstrated in animals which are simply shown food (Fig. I). Teleologically one can see the advantage of such a reflex to the animal since nutrient absorption can be faster 
than insulin's glucose-clearing effect. There are marked differences in vagal responses between lean and congenitally obese $f a / f a$ rats and both hyperinsulinaemia and hypersecretion in the $f a / f a$ rat is partially vagally mediated (Rohner-Jeanrenaud et al. 1983). It is thus possible that some obesity syndromes are related to abnormal hypothalamic activity causing increased vagal signalling to the pancreas and leading to hyperinsulinaemia.

Control from the gut. The entero-insular axis has long been understood to have both neural and hormonal elements. Experiments by Poulsen et al. (1983) showed that sectioning of the nerves between the gut and the pancreas led to prompt abolition of the PP response to fundal distension, indicating that there were large neural elements in this reflex arc. It does seem, however, that most of the augmentation of pancreatic secretion is mediated hormonally by gastric inhibitory polypeptide, CCK, secretin and other gut hormones (Holst et al. 1980).

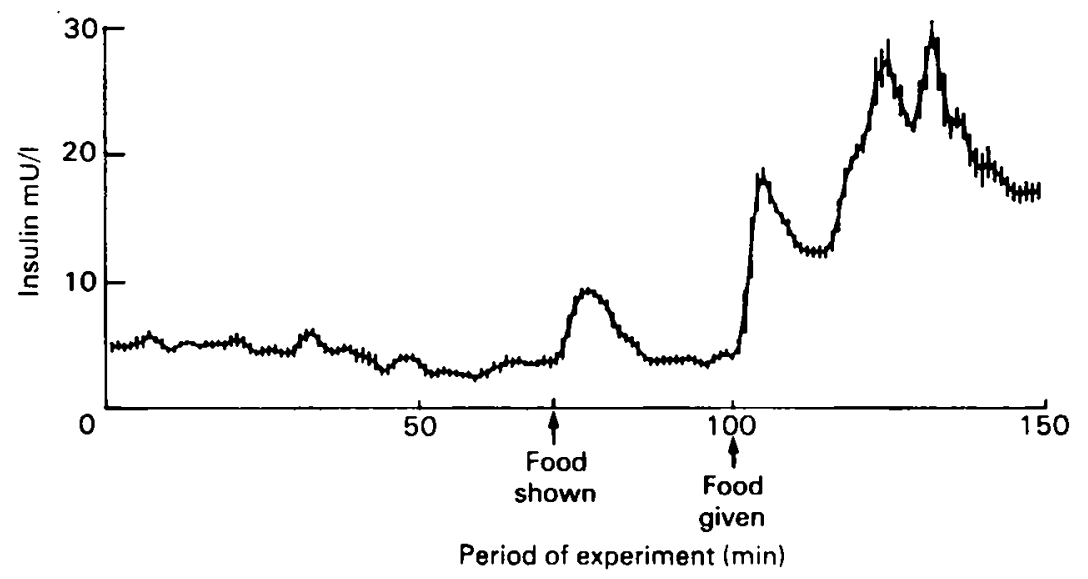

Fig. I. Cephalic phase reflex shown in conscious sheep. Portal insulin concentrations as sheep was shown food $(70 \mathrm{~min})$ and later given food $(100 \mathrm{~min})$. Values are 3 -min moving averages with their standard errors represented by vertical bars.

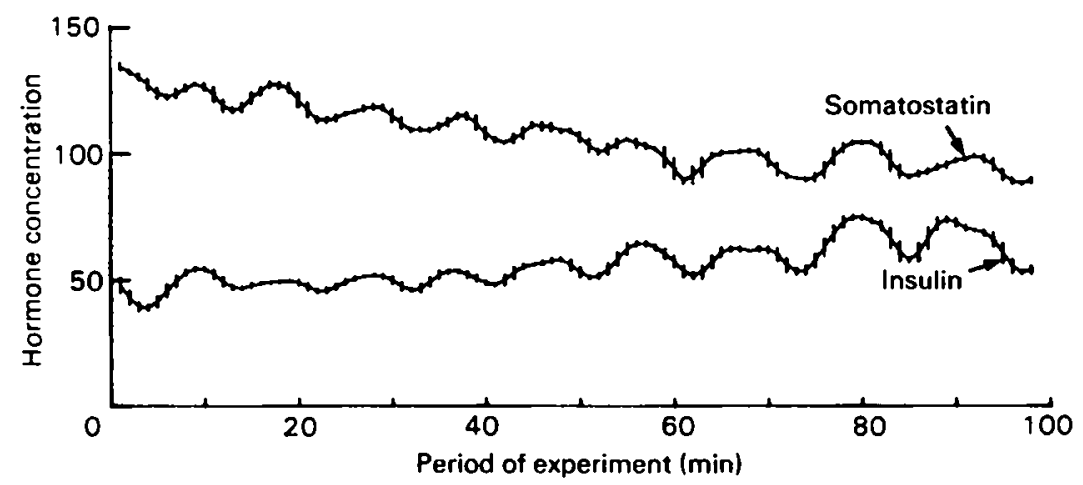

Fig. 2. In-phase secretion of somatostatin $(\mathrm{pg} / \mathrm{l})$ and of insulin $(\mathrm{pg} / \mathrm{ml})$ in the effluent of an isolated perfused dog pancreas. Values are 3 -min moving averages with their standard errors represented by vertical bars. 


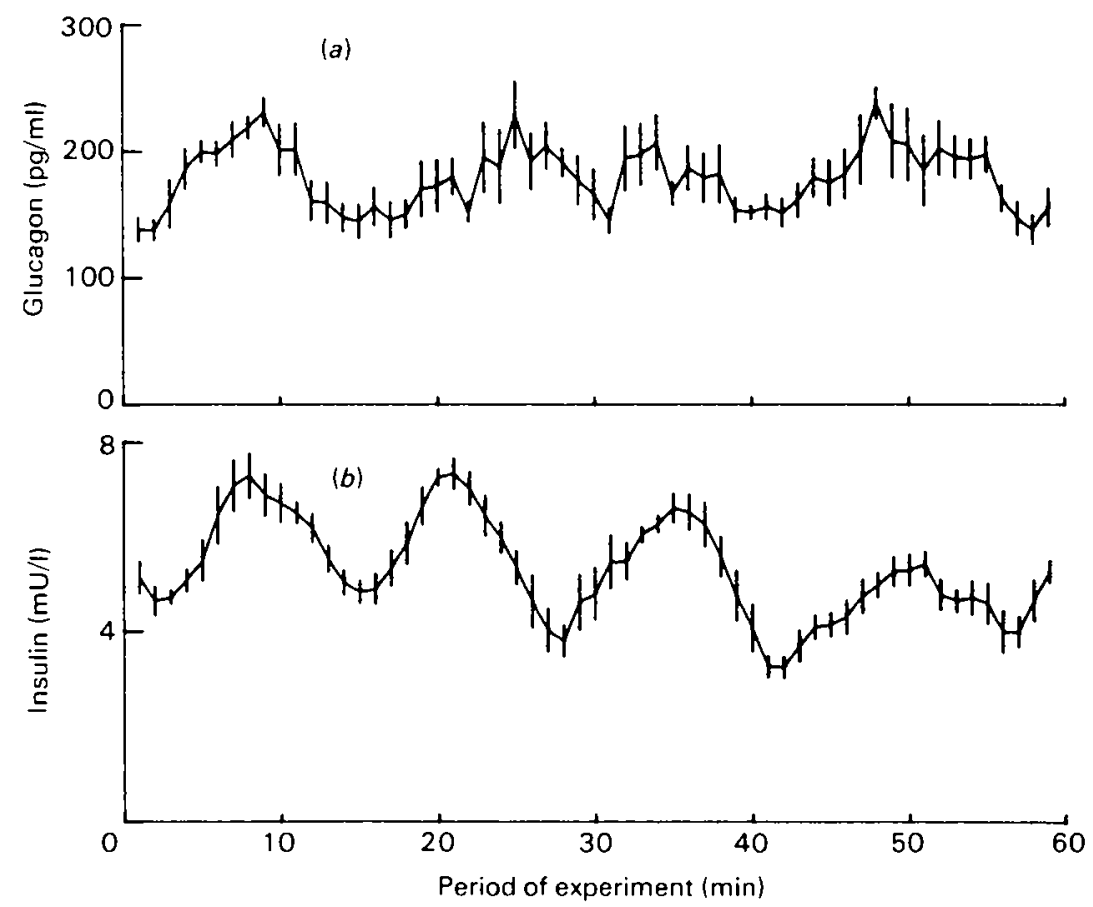

Fig. 3. In-phase $(a)$ glucagon and $(b)$ insulin concentrations in venous blood of normal fasting man. Values are 3 -min moving averages with their standard errors represented by vertical bars.

Control within the pancreas. Insulin secretion from the pancreas is not simply a function of substrate level. Oscillations in insulin secretion occur autonomously, and these can be demonstrated in isolated perfused preparations (Fig. 2), whilst in dogs it seems that somatostatin secretion is in phase with insulin and may be a coordinating signal. In man glucagon secretion, though not PP, is also entrained with insulin (Lang et al. 1982) (Fig. 3). Since these phenomena are demonstrable using the isolated perfused pancreas, the control of the basal secretion of hormones would need to be co-ordinated or initiated within the pancreatic structure itself (Stagner \& Samols, 1985). The anatomical observation that extrinsic denervation of the pancreas does not lead to degeneration of the intrinsic nervous elements suggests the presence of an autonomous internal nerve network which could have a role as an active functional integrating mechanism between the islets. Furthermore it is possible that within the pancreas there is an anatomically definable 'pacemaker' (Lang et al. 1979) or that summation of small signals may lead to oscillatory insulin release from the whole organ. The fact that glucagon, insulin and somatostatin are secreted in phase with each other (Lang et al. 1982) means that the integration may be both intra-islet as well as inter-islet. It is possible that the inter-islet signals are neural and intra-islet signalling could occur on a paracrine basis since there are now observations on the portal nature of the islet circulation (Bonner-Weir \& Orci, 1982). 


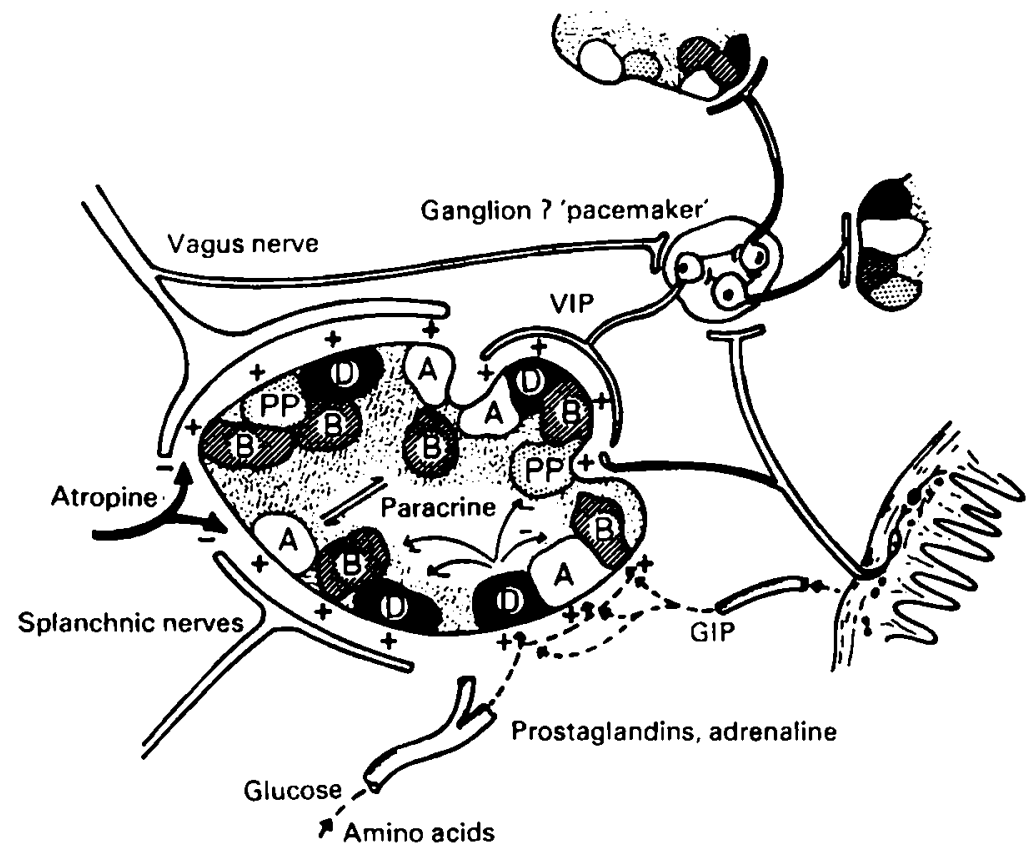

Fig. 4. Nervous and hormonal pathways influencing islet secretion. Hormone release from A, B, D and PP cells effected by vagal and splanchnic nerve stimulation is blocked by atropine. Secretion is also affected by blood-borne vasoactive substances (e.g. gastric inhibitory polypeptide (GIP), glucose, adrenaline). Intrinsic intestinal polypeptide (VIP)-containing nerves may connect ganglia and islets to form a pancreatic 'pacemaker'.

The evidence that insulin oscillations are themselves important stems from observations that maturity-onset diabetics may produce a sufficient quantity of insulin but seem to produce this in an erratic and non-oscillatory way (Lang et al. 1981). There is now evidence which suggests that insulin pulsations have a greater hypoglycaemic effect than steady insulin when administered in equivalent doses (Matthews et al. $1983 b$ ). In addition, patients receiving either Whipples operation or truncal vagotomy, resulting in a denervated pancreas, seem to show an impairment of glucose tolerance (Matthews et al. 1983a). Examining their oscillatory insulin production demonstrated that they have a substrate-induced feedback cycle of $37-40$ min duration but did not have the short intrinsic insulin secretory oscillations of $\mathrm{I}_{2-14} \mathrm{~min}$ seen in young, normal subjects. Somatostatin-secreting cells may themselves be the modulating stimulus, having a marked suppressor effect on insulin secretion. Thus D-cells could function as the focus of a local paracrine system inside the pancreatic islets inducing periodic suppression of insulin and glucagon secretion followed by a rebound (Matthews et al. 1986). It is possible that inter-islet signalling may be a paracrine phenomenon but the VIP-containing nerves, known to be present in large numbers around the islets, could integrate and coordinate activity between the islets. 


\section{Conclusions}

Anatomical studies indicate abundant evidence for the multiple innervation of pancreatic islets (Fig. 4). Physiological studies show that many of the secretory phenomena of the pancreas are directly under neuronal influence, especially via the vagus, splanchnic, and VIP-containing nerves. There is now increasing evidence for control of secretion from higher centres involving both cephalic phase insulin secretion and control of pulsatile insulin secretion. It is possible, that the pathological states of hypothalamic obesity or genetic obesity are mediated via vagal pathways, and that the innervation of the pancreas is controlling secretion mediated through local signals from the gut as part of the entero-insular axis. Finally, there is an increasing body of evidence related to intra-pancreatic coordination between the Islets of Langerhans whereby insulin, glucagon and somatostatin are secreted in phase. This is important to glucose homeostasis and can be influenced by vagotomy both in dogs and in man.

DRM is a Joan \& Richard Doll Research Fellow at Green College and Honorary Consultant Physician.

\section{REFERENCES}

Ashcroft, S. J. H. (1980). Diabetologia 18, $5^{-15}$.

Bernard, C. (1 849). Comptes Rendus Societe Biologie (Paris) 1, 60.

Berthoud, H. R. \& Jeanrenaud, B. (I982). American fournal of Physiology 242, E280-E285.

Bishop, A. E., Polak, J. M., Green, I. C., Bryant, M. G. \& Bloom, S. R. (1980). Diabetologia 18, $73-87$.

Bloom, S. R. \& Edwards, A. V. (1980). Journal of Physiology 308, 39-41.

Bonner-Weir, S. \& Orci, L. (1982). Diabetes 31, 883-889.

Frohman, L. A., Ezdinli, E. Z. \& Javid, R. (1967). Diabetes 16, 443-448.

Holst, J. J., Knuhtsen, S., Jensen, S. L., Fahrenkrug, J., Larrson, L.-I. \& Nielsen, O. V. (I983). Scandinavian 7ournal of Gastroenterology $18,85-99$.

Holst, J. J., Jensen, S. L., Schaffalitzky de Muckadell, O. B. \& Fahrenkrug, J. (1980). Frontiers of Hormone Research 7, 1 19-131.

Lang, D. A., Matthews, D. R., Peto, J. \& Turner, R. C. (1979). New England Journal of Medicine 301, 1023-1027.

Lang, D. A., Matthews, D. R. \& Turner, R. C. (198I). Diabetes 30, 435-439.

Lang, D. A., Matthews, D. R., Ward, G. M., Burnett, M. A. \& Turner, R. C. (1982). Diabetes 31, 22-26.

Langerhans, P. (1869). Inaugural Dissertation. Berlin: G. Lange.

Larsson, L.-I. (1 979). Fournal of Histochemistry and Cytochemistry $27,1283^{-1284}$.

Larsson, L.-I., Goltermann, N., Magistris, L., Rehfeld, J. F. \& Schwartz, T. W. (1979). Science 205, $1393-1395$.

Matthews, D. R., Hermansen, K., Connolly, A. A., Gray, D., Schmitz, O., Clark, A.. Darling. P.. Orskov, O. \& Turner, R. C. (1986). Endocrinology (In the Press).

Matthews, D. R., Lang, D. A., Burnett, M. A. \& Turner, R. C. $(1983 a)$. Diabetologia $24,231-237$.

Matthews, D. R., Naylor, B. A., Jones, R. G., Ward, G. M. \& Turner, R. C. (1983b). Diabetes 32, 6I $7-621$.

Porte, D., Giradier, L., Seydoux, J., Kanazawa, Y. \& Pasternak, J. (1973). Journal of Clinical Investigation 52, $210-214$.

Poulsen, J., Delikaris, P., Lovgreen, N. A. \& Schwartz, T. W. (1983). Scandinavian fournal of Gastroenterology 18, 1 7-22. 


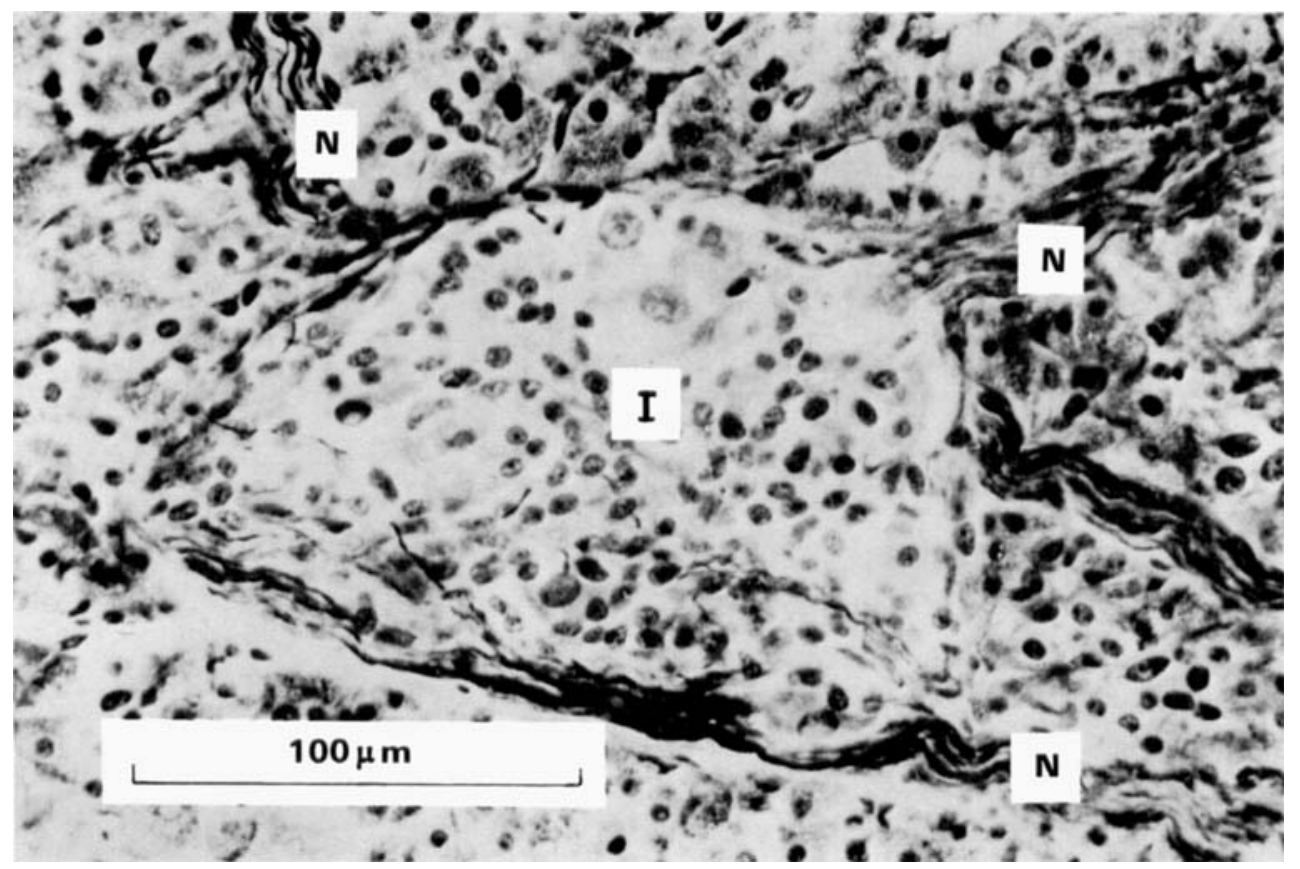


Vol. 46

Rohner-Jeanrenaud, F., Hochstrasser, A.-C. \& Jeanrenaud, B. (1983). American fournal of Physiology 244, $\mathrm{E}_{31} 17-\mathrm{E}_{322}$.

Samols, E. \& Weir, G. C. (1979). Fournal of Clinical Investigation 63, 230-328.

Schwartz, T. W., Holst, J. J., Fahrenkrug, J., Jensen, S. L., Nielsen, O. V., Rehfeld, J. F., Schaffalitzky de Muckadell, O. B. \& Stadil, F. (1978). Fournal of Clinical Investigation 6r, $781-789$.

Schwartz, T. W., Rehfeld, J. F., Stadil, F., Larsson, L.-I., Chance, R. E. \& Moon, N. (1976). Lancet i, $1102-1105$.

Stagner, J. I. \& Samols, E. (1985). American fournal of Physiology 248, $\mathrm{E}_{51} 6-\mathrm{E}_{521}$.

Szecowka, J., Sandberg, E. \& Efendic, S. (1980). Diabetologia 19, 137-142.

\section{EXPLANATION OF PLATE}

Plate I. Nerve supply to a human pancreatic islet. Nerve bundles (N) pass through the exocrine tissue to the islet (I). Fine nerve fibres can be seen within the islet. Palmgren's silver stain. 